\section{Case Reports in Neurology}

Case Rep Neurol 2020;12:149-155

DOI: 10.1159/000501069

Published online: December 14, 2020 (c) 2020 The Author(s)

Published by S. Karger AG, Basel OPEN www.karger.com/crn

This article is licensed under the Creative Commons Attribution-NonCommercial 4.0 International License (CC BY-NC) (http://www.karger.com/Services/OpenAccessLicense). Usage and distribution for commercial purposes requires written permission.

\title{
Cough-Induced Extracranial Internal Carotid Artery Dissection
}

\author{
Mei-Ling Sharon Tai ${ }^{a}$ Sheau Fung Sia ${ }^{b}$ Khairul Azmi Abdul Kadir ${ }^{c}$ \\ Mohamad Imran Idris ${ }^{a}$ Kay Sin Tan ${ }^{a}$ \\ aDivision of Neurology, Department of Medicine, Faculty of Medicine, University of \\ Malaya, Kuala Lumpur, Malaysia; 'bivision of Neurosurgery, Department of Surgery, \\ Faculty of Medicine, University of Malaya, Kuala Lumpur, Malaysia; 'Department of \\ Biomedical Imaging, Faculty of Medicine, University of Malaya, Kuala Lumpur, Malaysia
}

\section{Keywords}

Dissection · Internal carotid artery $\cdot$ Extracranial $\cdot$ Respiratory tract infection $\cdot$ Cough $\cdot$ Stroke

\begin{abstract}
Background: Coughing due to respiratory tract infections may lead to internal carotid artery (ICA) dissection. Aim: We are presenting a patient with an unusual cough-induced ICA dissection. Case Report: A 42-year-old health care worker presented with bilateral hand numbness which resolved spontaneously. This initial episode was followed 9 days later with intermittent episodes of right hand and leg weakness with speech difficulty. Two days later, he had another episode of speech difficulty. One week prior to the first presentation, he had upper respiratory tract infection with ongoing strong bouts of coughing. Magnetic resonance imaging (MRI), diffusion-weighted imaging (DWI), and apparent diffusion coefficient (ADC) of the brain showed early ischaemic changes at the left frontal and left parietal regions. MR angiography (MRA) showed high signal intensity at the left proximal ICA and poor flow beyond the left carotid bulb. Cerebral angiography revealed left ICA dissection. Conclusion: Proper identification of cough-induced extracranial ICA dissection is important because this is treatable.
\end{abstract}




\section{Case Reports in Neurology}

Case Rep Neurol 2020;12:149-155

DOI: 10.1159/000501069

(c) 2020 The Author(s). Published by S. Karger AG, Basel www.karger.com/crn

Tai et al.: Cough-Induced Extracranial Internal Carotid Artery Dissection

\section{Introduction}

Internal carotid artery (ICA) dissection is one of the causes of stroke in young individuals [1]. Coughing due to respiratory tract infections can result in ICA dissection but this is rare [2]. ICA dissection can occur at the intracranial or extracranial carotid vessels [1]. We are presenting a patient with an unusual cough-induced extracranial ICA dissection.

\section{Case Report}

A 42-year-old male health care worker at the paediatric setting presented with bilateral hand numbness which resolved spontaneously. Eight days later, he experienced a 1-day history of intermittent episodes of acute onset of right hand weakness and right leg weakness. He had to drag his right leg while walking. He was unable to pull the toilet paper. He could not speak in complete full sentences. The duration for each episode was a few minutes.

He was admitted to a nearby hospital. The magnetic resonance imaging (MRI) of the brain showed infarcts at the left frontal and left parietal regions. He was discharged the next day. The following day after discharge, he had another episode of speech difficulty. He was subsequently admitted to our hospital. On further history taking, he told us that he had upper respiratory tract infection with strong bouts of coughing 1 week prior to the initial neurological complaints. He did not have chest pain or shortness of breath. He did not have vascular risk factors.

On examination, he was alert and conscious. Blood pressure was 125/84. Heart rate was 60 beats per minute and the pulse was regular. He had mild residual expressive dysphasia. He did not have receptive dysphasia or facial asymmetry. Neurological examination of the upper and lower limbs showed that power was $5 / 5$ in both upper and lower limbs. Tone was normal bilaterally. Reflexes were normal bilaterally. Plantar response was down going in both lower limbs. Cardiovascular examination was normal and he had no murmur.

Connective tissue disease screen was negative. Fasting lipid profile and fasting blood sugar tests were normal. Electrocardiography (ECG) and transthoracic echocardiography results were normal. The plain computed tomography (CT) of the brain on admission showed infarcts at the left frontal and left parietal regions. The time of flight (TOF) image of the magnetic resonance angiography (MRA) showing the dissection and thrombus at the left extracranial ICA is illustrated in Figure 1. The computed tomography angiography (CTA) of the brain demonstrated dissection of left ICA and thrombosis at mid segment of the left middle cerebral artery (MCA) (Fig. 2).

The diffusion-weighted imaging (DWI) and apparent diffusion coefficient (ADC) sequences of MRI of the brain showed early ischaemic changes at the left frontal, left parietal regions and left centrum semiovale (Fig. 3, 4). The fluid attenuation inversion recovery (FLAIR) sequence showed infarcts at the left frontal and left parietal regions. FLAIR sequence showing that the infarct on the central sulcus was post-central (parietal) was illustrated in Figure 3. MRA of the brain showed high signal intensity at the left proximal ICA and there was poor flow at the ICA beyond the left carotid bulb. Mild attenuation at the MI and M2 segments at the left MCA was seen.

The cerebral angiography revealed rat tail appearance at the left proximal ICA distal to the carotid bulb, consistent with left ICA dissection (Fig. 4). The patient was treated with subcutaneous (SC) enoxaparin with concurrent oral warfarin. SC enoxaparin was stopped when

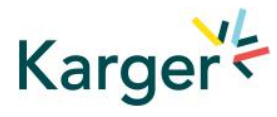




\section{Case Reports in Neurology}

Tai et al.: Cough-Induced Extracranial Internal Carotid Artery Dissection

the international normalized ratio (INR) was therapeutic. Oral warfarin was given for six months. At this time, repeat MRI of the brain showed resolution of the ICA dissection. Two and a half years after the dissection, he was well with minimal receptive dysphasia and he did not have recurrent stroke.

\section{Discussion}

We are presenting an interesting case of a patient who developed extracranial ICA dissection after a history of coughing bouts due to upper respiratory tract infection. To our knowledge, in the literature, there are only 81 reported cases on ICA dissection after infection or prolonged cough [1-6].

In this case, coughing caused a tear in the vessel wall, leading to thrombosis of the vessel. This was followed by artery to artery embolism. Therefore, we can postulate that the initial presentation was likely due to thrombosis causing left ICA occlusion, which caused non-specific bilateral hand numbness due to cerebral hypoperfusion. The second presentation of right-sided weakness was due embolism to the left frontal regions. As it usually takes time for thrombus formation and embolism to occur, clinical presentation usually takes place in a delayed manner after the time of dissection.

Recent respiratory tract infections can precipitate ICA dissection due to violent cough [2]. In a hospital-based case control study, acute infection was reported to be more common in patients with spontaneous cervical artery dissection (31.9\%) in comparison to healthy subjects (13.5\%) [1]. In addition to the mechanical factor induced by violent coughing, indirect inflammation and host response can contribute to ICA dissection [1]. The cytokine and proteases are stimulated, leading to increased extracellular matrix degradation and this weakens the vessel wall $[1,7]$. Recent infection has been reported to lead to extracranial ICA dissection by prothrombotic phenomenon or endothelial damage [8]. Furthermore, ICA dissection can occur due to oxidative or autoimmune mechanisms [7].

The incidence of carotid dissection is higher in the autumn season, during the period when there is a rise in respiratory infections [2]. Pertussis infection can cause severe and violent episodes of coughing leading to mechanical consequences such as arterial dissection in adults and children $[2,9]$.

Respiratory tract infections have been reported to result in intracranial extension of the ICA, such as petrous region in addition to cervical ICA involvement $[7,10]$. Moreover, vertebral artery dissection, usually at the distal aspect of the extracranial vertebral artery can also occur due to respiratory tract infections [7]. Only one study showed that recent infections including respiratory tract infections and skin infections were independently associated with cervical artery dissection [6].

Horner's syndrome is a feature of ICA dissection $[7,10]$. However, unusually this patient did not have signs of Horner's syndrome whether partial or complete. There are several neuroimaging modalities of extracranial ICA dissection [7, 10]. MRI/MRA is now the investigation of choice because it is non-invasive and it is useful for follow-up monitoring of the dissections [7]. The dissection is identified by demonstration of intramural haematoma (hyperdense signals on T1W) [7]. Doppler ultrasonography and CT angiography have high sensitivities. [7] The classic neuroradiological feature of dissection on cerebral angiography is "string sign" or "rat-tail sign" [7].

\section{Karger'=}




\section{Case Reports in Neurology}

\begin{tabular}{l|l}
\hline Case Rep Neurol 2020;12:149-155 \\
\hline DOI: 10.1159/000501069 & $\begin{array}{l}\text { @ 2020 The Author(s). Published by S. Karger AG, Basel } \\
\text { www.karger.com/crn }\end{array}$ \\
\hline
\end{tabular}

Tai et al.: Cough-Induced Extracranial Internal Carotid Artery Dissection

Extracranial ICA dissection presents with less severe cerebral infarcts compared to intracranial ICA dissection [7]. Therefore, the patients who develop extracranial ICA dissection have better prognosis than intracranial ICA dissection [7]. The preferred management in this condition is medical therapy [11]. The efficacy of antiplatelet and anticoagulant medications are similar in the prevention of ischaemic stroke and mortality in patients with symptomatic ICA dissection [11].

Recurrence of cerebral infarct occurs in $0.3-20 \%$ of these patients [11]. Most of the infarcts occur in the first month due to embolism from the thrombus situated at the area of dissection [11]. Due to risk of early recurrent infarcts, the anticoagulant is administered for 6 months [11].

The recanalization rate is high within the first 3 months after the carotid dissection [10]. The recurrence rate for carotid artery dissection is $2 \%$ in the first month, whereas the rate is only $1 \%$ in 1 year after the dissection [10]. After carotid dissection, approximately $3.4 \%$ of these patients have transient ischaemic attack (TIA), whereas 1\% develop retinal ischaemia eventually [11].

In conclusion, we would like to emphasize the importance of detailed history-taking for proper diagnosis of cough-induced extracranial ICA dissection, which is a treatable disease in patients with recent upper respiratory tract infections.

\section{Statement of Ethics}

The authors have no ethical conflicts to disclose. The patient gave informed consent for the publication.

\section{Conflict of Interest Statement}

The authors have no conflicts of interest to declare.

\section{Funding Sources}

The authors received no financial support for the research, authorship, and publication of this article.

\section{References}

1 Guillon B, Berthet K, Benslamia L, Bertrand M, Bousser MG, Tzourio C. Infection and the risk of spontaneous cervical artery dissection: a case-control study. Stroke. 2003 Jul;34(7):e79-81.

2 Skowronski DM, Buxton JA, Hestrin M, Keyes RD, Lynch K, Halperin SA. Carotid artery dissection as a possible severe complication of pertussis in an adult: clinical case report and review. Clin Infect Dis. 2003 Jan;36(1):e1-4.

3 Zank JS, Singh R, Carney M. Carotid Artery Dissection and Ischemic Stroke After Severe Coughing. Pediatr Emerg Care. 2016 Oct;32(10):693-5.

\section{Karger'=}




\section{Case Reports in Neurology}

\begin{tabular}{l|l}
\hline Case Rep Neurol 2020;12:149-155 \\
\hline DOI: 10.1159/000501069 & $\begin{array}{l}\text { @ 2020 The Author(s). Published by S. Karger AG, Basel } \\
\text { www.karger.com/crn }\end{array}$ \\
\hline
\end{tabular}

Tai et al.: Cough-Induced Extracranial Internal Carotid Artery Dissection

4 Viticchi G, Falsetti L, Baruffaldi R, Vernieri F, Altamura C, Bartolini M, et al. Acute carotid dissection in an adult caused by pertussis. J Stroke Cerebrovasc Dis. 2013 Nov;22(8):e635-6.

5 Levy M, Arfi-Levy E, Maimon S. Therapeutic and diagnostic implication of inadequate circle of willis in a patient with acute spontaneous bilateral internal carotid artery dissection: case report and review of the literature. Case Rep Neurol. 2012 Jan;4(1):1-9.

6 Grau AJ, Brandt T, Buggle F, Orberk E, Mytilineos J, Werle E, et al. Association of cervical artery dissection with recent infection. Arch Neurol. 1999 Jul;56(7):851-6.

7 Thanvi B, Munshi SK, Dawson SL, Robinson TG. Carotid and vertebral artery dissection syndromes. Postgrad Med J. 2005 Jun;81(956):383-8.

8 Debette S. Pathophysiology and risk factors of cervical artery dissection: what have we learnt from large hospital-based cohorts? Curr Opin Neurol. 2014 Feb;27(1):20-8.

9 Carey C. Post-tussive carotid artery dissection: could it be whooping cough? CMAJ. 2014 Jun;186(9):697.

10 Furlan JC, Sundaram AN. Sudden-onset anisocoria in a patient with upper respiratory tract infection. CMAJ. 2014 Jan;186(1):57-61.

11 Markus HS, Hayter E, Levi C, Feldman A, Venables G, Norris J; CADISS trial investigators. Antiplatelet treatment compared with anticoagulation treatment for cervical artery dissection (CADISS): a randomised trial. Lancet Neurol. 2015 Apr;14(4):361-7.

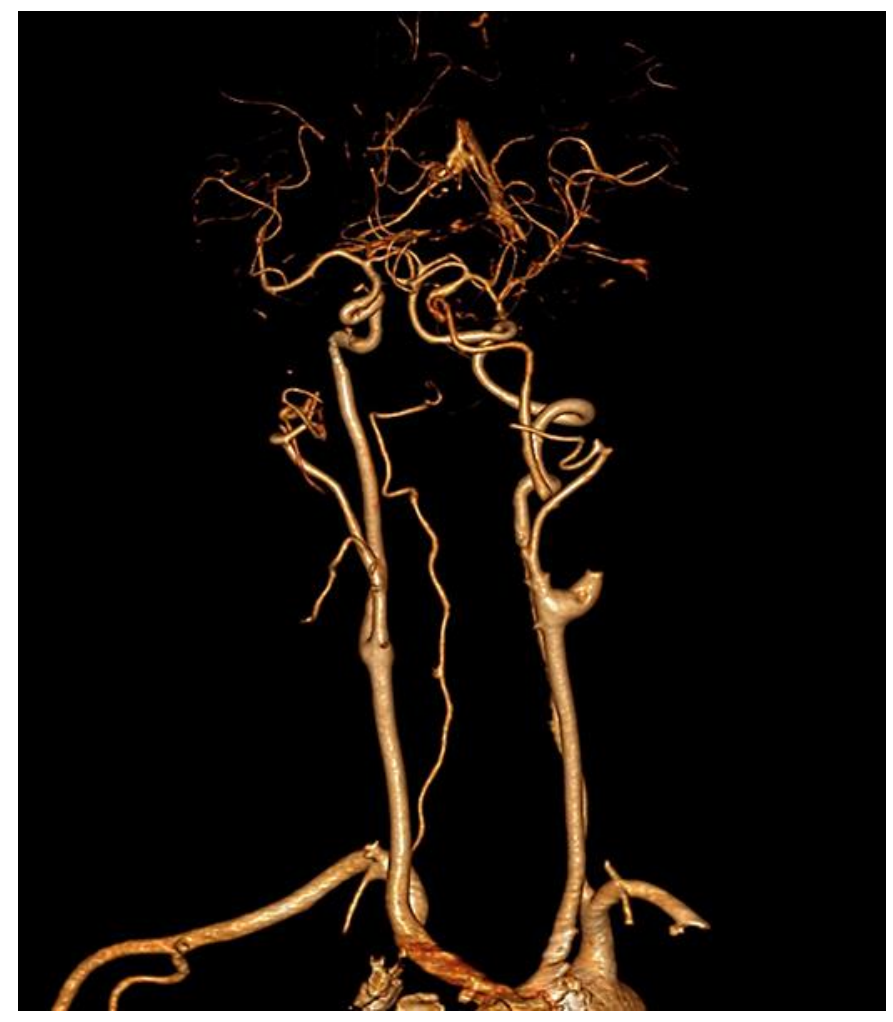

Fig. 1. CTA of the brain showed dissection of left ICA and thrombosis at mid segment of left MCA.

\section{Karger'}


Case Reports in Neurology
Case Rep Neurol 2020;12:149-155

DOI: 10.1159/000501069

(c) 2020 The Author(s). Published by S. Karger AG, Basel www.karger.com/crn

Tai et al.: Cough-Induced Extracranial Internal Carotid Artery Dissection

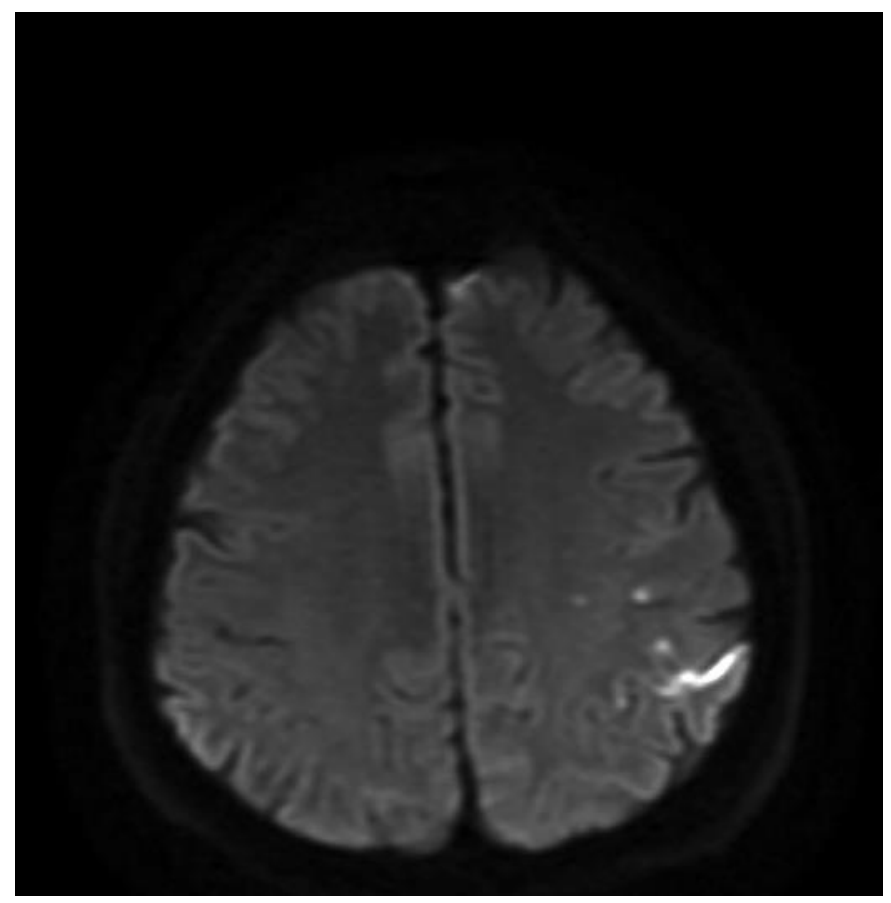

Fig. 2. The diffusion-weighted imaging (DWI) of MRI of the brain showed restricted diffusion at the left frontal and left parietal regions.

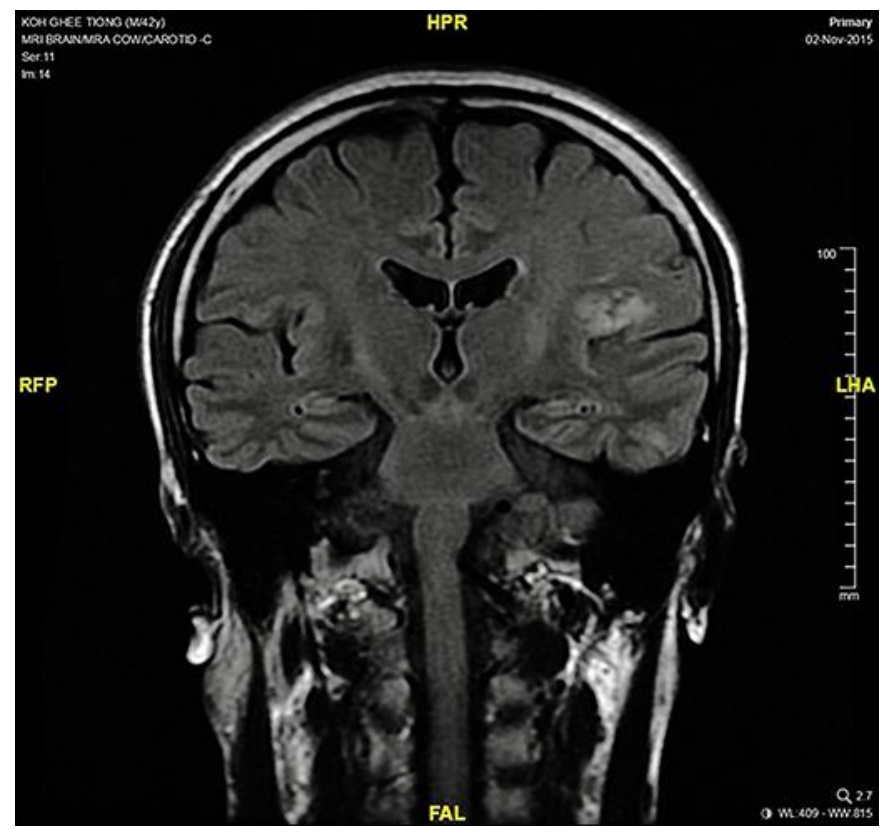

Fig. 3. Fluid attenuation inversion recovery (FLAIR) sequence showed that the infarct on the central sulcus was post-central (parietal). 
Case Reports in Neurology
Case Rep Neurol 2020;12:149-155 DOI: $10.1159 / 000501069$ 2020 The Author(s). Published by S. Karger AG, Basel Tai et al.: Cough-Induced Extracranial Internal Carotid Artery Dissection

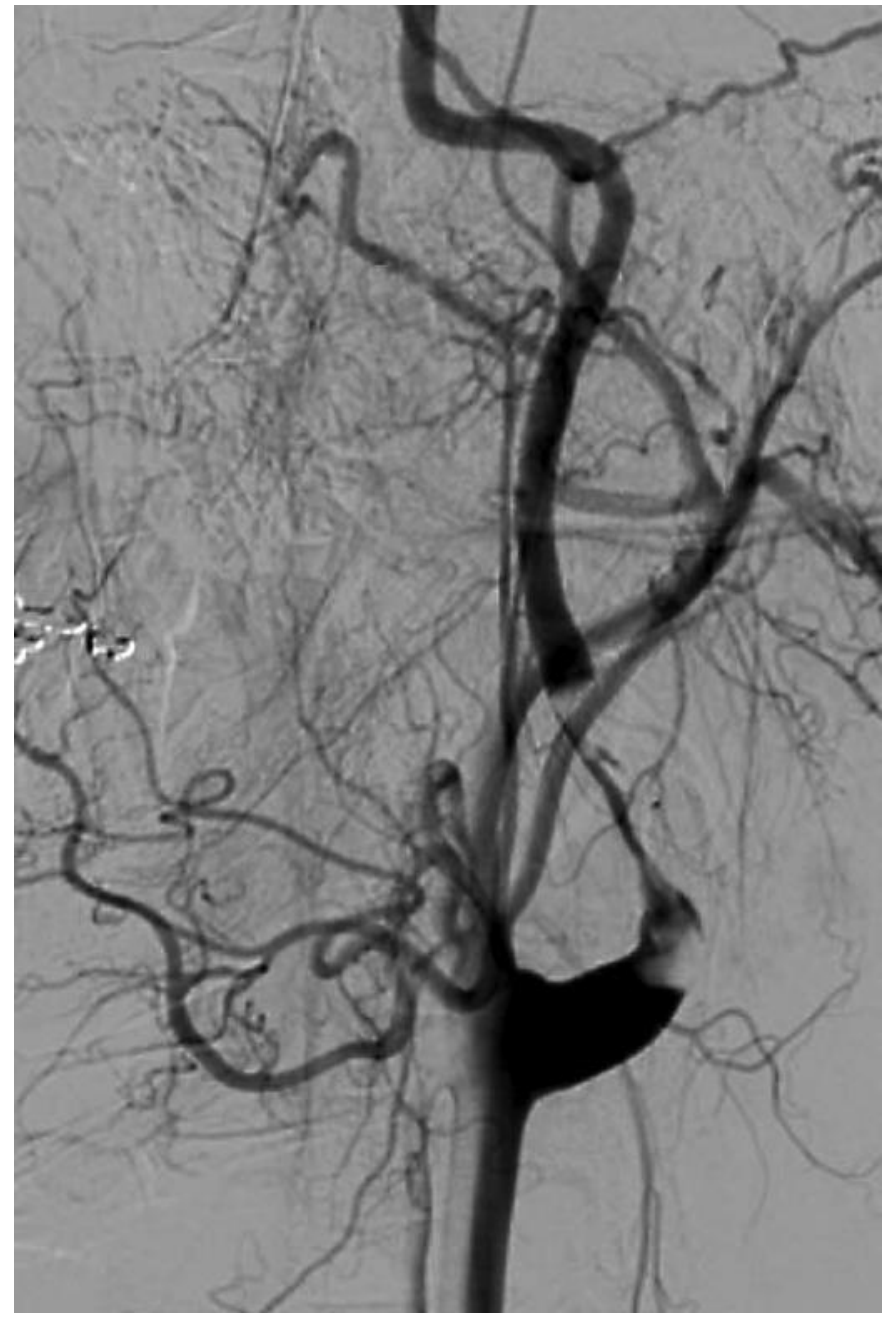

Fig. 4. Cerebral angiography showed rat tail appearance at the left proximal ICA distal to the carotid bulb, consistent with left ICA dissection. 